\title{
A Comparison of Self-Directed Learning and Lecture Methods for Teaching Embryology among First Year Medical Students
}

\author{
Dr. Vinay $\mathrm{G}^{1}$, Dr. Nagapraveen Veerapu ${ }^{2 *}$
}

1Professor \& Head, Department of Anatomy, Mamata Medical College, Khammam - 507002 Telangana India

2Assistant Professor, Department of Community Medicine, Mamata Medical College, Khammam - 507002 Telangana India

\author{
DOI: $10.36348 /$ sijap.2019.v02i12.003 \\ | Received: 05.12.2019| Accepted: 14.12.2019 | Published: 20.12.2019 \\ *Corresponding author: Dr. Nagapraveen Veerapu
}

\section{Abstract}

Teaching embryology seems to be a valuable part of the medical education and remains significant for facilitating undergraduates to appreciate the birth defects. In health care professional studies, self-directed learning (SDL) is considered an indispensable learning parameter. Numerous attempts have been made to compare lecture with alternative forms of self-directed learning. Objectives of the present study are - 1.To compares the effectiveness of self-directed learning with didactic lectures in learning embryology among first year medical students, 2.To assess the perception of students towards self-directed learning. This was a comparative study conducted on 80 Phase I MBBS students of Mamata Medical College. They were divided into 2 batches (Batch A and B) of 40 each. On the first day, Batch A was given a didactic lecture, while Batch B underwent a self-directed learning session with all the study materials provided. A pre and post-test questionnaire was administered. On the second day, the batches were reversed and another similar topic was dealt with. Perception towards Self-directed learning was collected using a pre-validated questionnaire. A paired ttest comparing both methods showed that the scores following self-directed learning were more compared to didactic lectures. Students choose self-directed learning as it improves the understanding of the subject and helps to clear up doubts. Embryology should be taught by different methods at the right level \& context.

Keywords: Effectiveness, Self-directed learning, Lecture, Embryology, Perception.

Copyright @ 2019: This is an open-access article distributed under the terms of the Creative Commons Attribution license which permits unrestricted use, distribution, and reproduction in any medium for non-commercial use (NonCommercial, or CC-BY-NC) provided the original author and source are credited.

\section{INTRODUCTION}

It is expected that a medical student will be a "lifetime learner". Self-directed learning (SDL) is described as the "preparedness of a student to engage in learning activities defined by himself rather than a teacher". It is considered an essential parameter of learning and extensively used in medical education [1].

Over the past few decades, new learning approaches such as self-directed learning have emerged in medical education with an emphasis on students taking the initiative in learning [2]. Different approaches to SDL have been used. Therefore, where the function of the lecture is increasing, the hybrid types of lecture and self-directed methods are also practiced [3, 4].

Several studies have shown that SDL is appreciated for learning gross anatomy and physiology in terms of knowledge gaining $[5,6]$. In the crowded medical curriculum, embryology is jostling for precious space, but it remains important to help students understand birth defects [7]. Embryology is hard to understand as it deals with minute structures and includes vibrant changes in an embryo's growth. It provides the basic knowledge of the human body and has applied significance [8].

Numerous attempts have been made to compare the didactic lecture method with alternative forms of self-directed learning. Therefore, the purpose of this study is to demonstrate the effectiveness of SDL in embryology learning and comparison with the lecture method of teaching.

\section{OBJECTIVES}

- To compare the effectiveness of self-directed learning (SDL) with didactic lectures in learning embryology among first year medical students

- To assess the perception of students towards selfdirected learning. 


\section{MATERIAL \& METHODS}

After obtaining institutional ethics committee clearance, 80 first-year undergraduate medical students were included in this study. This comparative study was carried out at the department of Anatomy, of a private medical college, Khammam, India from June 2019 to September 2019. The student who volunteered were included and those were unable to attend were excluded from study. Consent was taken from the students. Students were divided into 2 batches (Batch A and B) of 40 each. On the first day, Batch A was taught by didactic lecture method on the topic "Development of Eye", in the usual format. A pre and post-test MCQ was administered.

While Batch B was having a self-directed learning session for one hour. The material for SDL was prepared by building a case scenario regarding the development of the eye and its applied anatomy. Students were requested to bring their textbooks, reference material, and handouts of power point presentation were given. The pre-test and post-test questionnaires were given just before and after the SDL sessions.

On the second day, the batches were crossed over and the topic "Development of Ear" was dealt with a didactic lecture for Batch B and Self-directed learning for Batch A. Pre-test and post-test questions were administered. Learning outcomes and knowledge were assessed by comparing the pre-test and post-test scores on MCQ in both the methods. The Perceptions of students towards SDL was assessed using a structured pre-validated questionnaire.

\section{STATISTICAL ANALYSIS}

The data were analysed using the SPSS software version 20 . The mean, standard deviation was calculated. The pre-test and post-test results of conventional lecture and SDL were analysed using the paired t-test. $\mathrm{P}$ valve less than 0.05 was considered significant.

\section{RESULTS}

The mean and standard deviation of pre-test and post-test of the SDL \& lecture method were shown in Figures $1 \& 2$. The mean score of the students in SDL method was more than the lecture method (Table: $1)$ and was statistically significant $(P \leq 0.05)$.

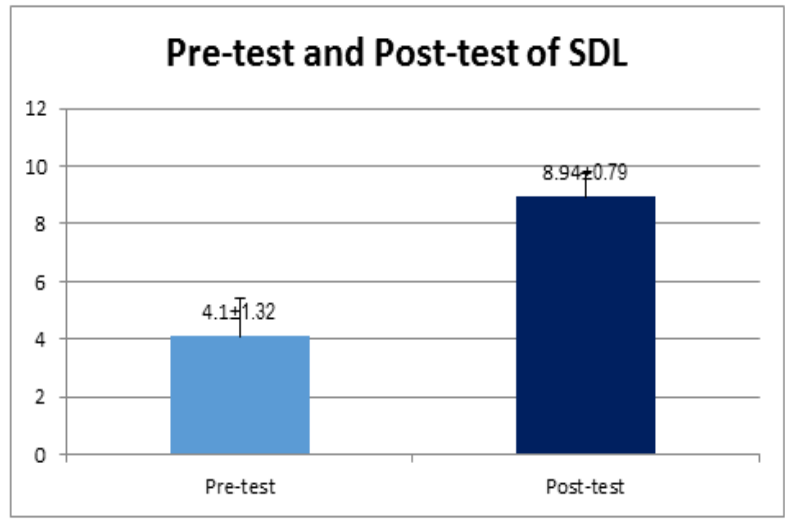

Fig-1: Comparing the pre-test and post test scores of SDL

Paired t-test, P-value $=0.0001$

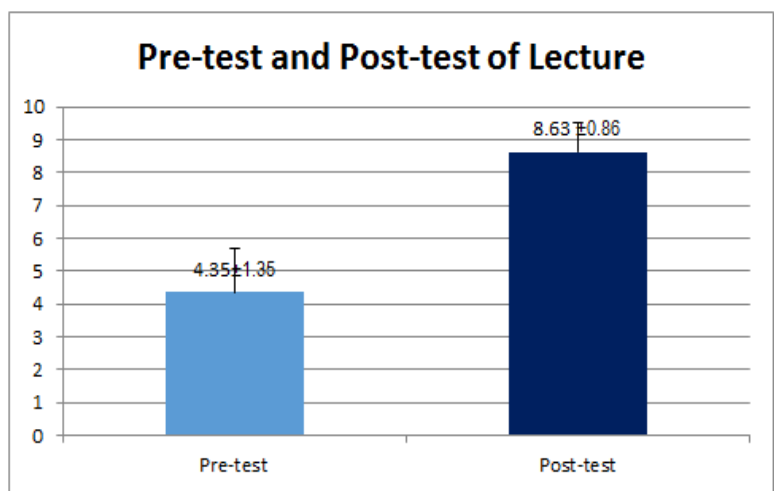

Fig-2: Comparing the pre-test and post test scores of Lecture method

Paired t-test, $\mathrm{P}$-value $=0.0001$

Table-1: Comparison of post-test scores of SDL and lecture methods

\begin{tabular}{|l|l|l|}
\hline Methods & Mean & SD \\
\hline SDL & 8.94 & 0.785 \\
\hline Lecture & 8.63 & 0.862 \\
\hline
\end{tabular}

Independent t-test, $\mathrm{P}$ - value $=0.018$

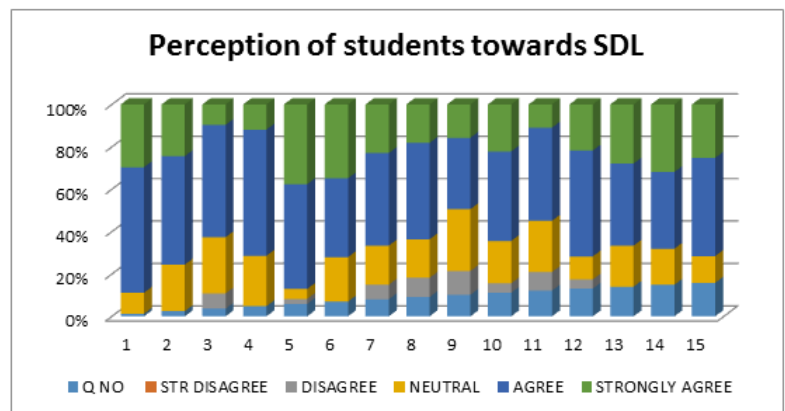

Fig-3: Showing the perceptions of students towards SDL

\section{DISCUSSION}

Anatomy teaching involves gross, histology as well as embryology. Gasping anatomy knowledge and applying it in clinical medicine is important for medical students [9]. Traditionally, teaching anatomy has involved students memorizing huge amounts of factual information without a great deal of understanding of their significance [10]. 
Embryology remains a significant tool in medical science for the management of numerous clinical situations [11]. Embryology instruction has lost ground in many of the medical colleges [12]. The lecture method is an extensively used technique in India for taking theory classes. It can also save the learner's time by providing an up to date summary of the topic from several sources. Nevertheless, this approach has many disadvantages. The student's passive nature and minimal input resources lead to low interest. Numerous students attend lecture classes due to compulsory attendance and fear of professors who may be their examiner [13].

SDL will contribute to an enhanced understanding of the topic, clear doubts, and better examination performance. Murad et al. concluded that SDL is a potential methodology in medical education to endorse lifelong learning. With the arrival of new content and competency based medical education involving SDL, medical teachers have become gradually interested in SDL method [14].

As per the study conducted by Anita et al $57.20 \%$ of the students agree that SDL is a timeconsuming method of learning. They also found that SDL encourages students to actively participate leading to active learning with better recall and develop good communication skills [15].

The present study shows that, relative to the lecture method, the gain in information was significant in the SDL method. This shows that in learning embryology topics, the SDL session was more effective. Many references have established that the SDL method is more effective than the traditional method of lecture similar to the results of this study.

Eighty-five percent of students in the study conducted by Hamilton et al. believed that clinical cases and questions would help with learning and applying embryology. Few students felt that teaching embryology should be more interactive. Medical students value the embryology teaching but find the subject tough to learn and apply in clinical practice [11].

Murad et al. implied that SDL is more suitable for adult learners who already have a reservoir of knowledge and can apply their learning immediately to their practices [14]. A study conducted by Abraham et al. to determine the effectiveness of SDL, exam scores of lecture method were significantly lower than SDL exam scores. These results suggest that SDL may be an effective learning tool. Furthermore, feedback from the students showed more of a positive approach towards SDL [16].

\section{CONCLUSION}

The teaching of embryology seems to be a necessary part of medical education. Embryology should be taught by different methods, including basic concepts, at the right level and context. SDL is an innovative embryology teaching method. This approach has also helped students improve communication skills.

The lecture method is also effective when used with various audio-visual aids to convey the intended knowledge. Students prefer SDL as it strengthens the subject's comprehension and helps to clear the doubts. SDL inspires students to dynamically participate leading to active and lifelong learning in medicine.

\section{ACKNOWLEDGEMENT}

We thank our Dean, Vice Principal, colleagues, students and non-teaching staff who have helped in this study.

\section{Abbreviations \\ 1) SDL - Self-directed learning}

\section{REFERENCES}

1. Premkumar, K., Pahwa, P., Banerjee, A., Baptiste, K., Bhatt, H., \& Lim, H. J. (2014). Changes in selfdirected learning readiness in dental students: a mixed-methods study. Journal of dental education, 78(6), 934-943.

2. Barrows, H. S. (1983). Problem-based, selfdirected learning. Jama, 250(22), 3077-3080.

3. Clough, R. W., Shea, S. L., Hamilton, W. R., Estavillo, J. A., Rupp, G., Browning, R. A., \& Lal, S. (2004). Weaving basic and social sciences into a case-based, clinically oriented medical curriculum: one school's approach. Academic Medicine, 79(11), 1073-1083.

4. Benedict, N., Schonder, K., \& McGee, J. (2013). Promotion of self-directed learning using virtual patient cases. American Journal of Pharmaceutical Education, 77(7), 151.

5. Arroyo-Jimenez, M. D. M., Marcos, P., MartinezMarcos, A., Artacho-Pérula, E., Blaizot, X., Muñoz, M., \& Insausti, R. (2005). Gross anatomy dissections and self-directed learning in medicine. Clinical Anatomy: The Official Journal of the American Association of Clinical Anatomists and the British Association of Clinical Anatomists, 18(5), 385-391.

6. Grieve, C. (1992). Knowledge increment assessed for three methodologies of teaching physiology. Medical teacher, 14(1), 27-32.

7. Scott, K. M., Charles, A. R., \& Holland, A. J. (2013). Clinical embryology teaching: is it relevant anymore?. ANZ journal of surgery, 83(10), 709712.

8. Moraes, S. G., \& Pereira, L. A. V. (2010). A multimedia approach for teaching human embryology: Development and evaluation of a 
methodology. Annals of Anatomy-Anatomischer Anzeiger, 192(6), 388-395.

9. Marcos, P., Arroyo-Jimenez, M. M., ArtachoPerula, E., Martinez-Marcos, A., Blaizot, X., Alfonso-Roca, M. T., \& Insausti, R. (2020). Selfdirected learning in the Gross Anatomy medical curriculum. European Journal of Anatomy, 8(3), 147-153.

10. Turney, B. W. (2007). Anatomy in a modern medical curriculum. The Annals of The Royal College of Surgeons of England, 89(2), 104-107.

11. Turney, B. W. (2007). Anatomy in a modern medical curriculum. The Annals of The Royal College of Surgeons of England, 89(2), 104-107.

12. Carlson, B. M. (2002). Embryology in the medical curriculum. The Anatomical Record: An Official Publication of the American Association of Anatomists, 269(2), 89-98.
13. Shankar, N., \& Roopa, R. (2009). Evaluation of a modified team based learning method for teaching general embryology to 1 st year medical graduate students. Indian journal of medical sciences, 63(1), 4-12.

14. Murad, M. H., Coto-Yglesias, F., Varkey, P., Prokop, L. J., \& Murad, A. L. (2010). The effectiveness of self-directed learning in health professions education: a systematic review. Medical education, 44(11), 1057-1068.

15. Gune, A. R., More, S. S., Satpue, S. P., Wagh, D. T., \& Nikam, V. R. Perception of First Year MBBS Students on Self-Directed Learning in Anatomy: Improves Concept, Retention and Communication skills.

16. Abraham, R. R., Upadhya, S., \& Ramnarayan, K. (2005). Self-directed learning. Advances in physiology education, 29(2), 135-136. 